\title{
Spaces of Transformative Practice: Co-producing, (Re)Making and Translating Fractional Urban Space in Gugulethu, Cape Town
}

\author{
Kathryn Ewing ${ }^{1}$ (1)
}

Accepted: 16 July 2021 / Published online: 31 July 2021

(C) The Author(s), under exclusive licence to Springer Nature B.V. 2021

\begin{abstract}
Reimagining neglected urban space offers the potential for social cohesion, integration, and connectivity. The intimate, interstitial or fractional spaces of a city represent a key component of social infrastructure in a neighbourhood. The smallest of interventions in urban space adds value and complexity to urban life. However, fractional, yet deeply transformative, urban space is often unrecognised and undocumented. Transformative practice seeks to accommodate, anticipate and represent inclusive public life but requires discovering new content and definitions on public space to decode emerging processes of incremental place-making in an African context. The narrative focuses on a network of place-making intervention projects as part of an urban upgrading programme in Lotus Park informal settlement, located in Gugulethu, Cape Town. A set of tracings, integrated with theoretical frames, reveal the impact of upgraded urban space through firstly, emerging centres and the (re) making of place on the periphery; secondly, disrupting edges and the co-production process involved in the negotiation of space; and lastly, crafting shadows and interpreting traces of micro-interventions. The purpose is to explore urban space as continually adapting to the intrusions in the city grid to translate (1) innovative modes of spatial production; (2) dynamic forms of local agency; (3) marginal ways of operating; and (4) interconnected and multi-scalar urban processes of everyday place-making. The practice of co-producing and (re)making urban space in Gugulethu uncovers alternate mechanisms for governance, partnerships and operations.
\end{abstract}

Keywords Urban fractional space $\cdot$ Transformative practice $\cdot$ Co-production $\cdot$ Placemaking

\footnotetext{
It is acknowledged the original paper was conceptualised by the author and submitted for the conference AAPS 2021 Urban Africa in the Twenty-First Century: Current Issues and Future Prospects of Urban Governance and Planning, Dar-es-Salaam, hosted by Institute of Spatial Planning (IRPUD), TU Dortmund University (Germany), Institute of Human Settlement Studies and School of Spatial Planning and Social Sciences, Ardhi University (Tanzania) and Association of African Planning Schools (AAPS) due to take place in 2021.
}

Extended author information available on the last page of the article 


\section{Fractional Urban Spaces: An Introduction}

Many cities in the global south experience radical transformation, where change manifests itself most evidently through space. COVID-19 has exposed vulnerable, yet flexible (informal) urban spaces as important collective places or public commons for practice, learning and exchange. The intimate, ordinary and interstitial spaces of a city represent a key component of social infrastructure in a neighbourhood. They are audible, active spaces loaded with local community dynamics, leadership battles and rights, rich in diversity and function. The design of urban space, if open and democratic, presents the possibilities of spatial justice. Re-imagining neglected and under-utilised spaces in the city's marginal neighbourhoods holds capacity for integration and social cohesion. The smallest of public interventions add value, care and complexity to urban life. Transformative practice seeks to accommodate inclusive public life but requires discovering new content and definitions on public space to translate emerging processes of incremental place-making in context.

Differences between practice, theory and policy are still severely disparate in urban South Africa. The random interaction of these spheres, combined with regulations and the burden of apartheid, echoed with modernist planning, repeatedly determines the fragmented urban form and impact of inequality and violence in the public realm. Public space is often misinterpreted, undervalued and represented in a technical planning or theoretical language, where one-size-fits-all. Modernist EuroAmerican centric notions of public space are brought into question in the neighbourhood of Gugulethu in Cape Town. The area is considered "pseudo-suburban" (Mabin et al., 2013, p. 171) in an African city context. Originally a location of racial separation with basic housing and low-quality formal public spaces, loaded with barriers of access to facilities, present the current day neighbourhood with underused, tolerated "green" infrastructure (Venter et al., 2020) combined with interstitial "grey" (Yiftachel, 2009) fractal space.

The myriad of urban space configurations in Gugulethu experience varying levels of exposure, accessibility and safety, where most struggle to be politically acknowledged. Conventional mono-functional parks, sports fields, open space and green infrastructure, zoned and administered as public open space, are largely neglected or under-utilised, shown as "low greenery" and resulting in spatial inequity or continual "green apartheid"(Venter et al., 2020). Municipal public space by-laws ${ }^{2}$ are focused around excluding marginal groups from formal public space, thereby if monitored, strictly control how public space is used and governed.

In comparison, grey urban spaces in Gugulethu have thrived as creative sites for micro-economies, spatial landmarks and makeshift safe places to gather. Based on student social mapping, analysis reveals that Gugulethu thrives on the informal social production in ordinary urban spaces connected to everyday practice and

\footnotetext{
1 Gugulethu mapped on green-apartheid.zsv.co.za.

2 The City of Cape Town by-law on Streets, Public Places and Prevention of Noise Nuisances (2007), and recently amended in 2020, regulates the conduct of individuals in public spaces. See https://openb ylaws.org.za/za-cpt/act/by-law/2007/streets-public-places-noise-nuisances/eng
} 
routine. Street life is stimulated along an energy line of local spaza shops and hair salons acting as community and economic centres by day. By night, the energy becomes dispersed points, randomly and discreetly located as gathering hubs in shabeens and taverns (drinking spots). The energy grid extends to a web of community gardens and informal early childhood development (ECD) facilities working as protected havens that function as productive social environments. Informal kickabout spaces operate as multi-functional 24-7 safe zones, and youth Wi-Fi hotspots perform as fragments of positive spatial occupation, influencing the formal network.

A reframing of the definition and role of public space in Gugulethu explores the concept of fractional urban space. ${ }^{3}$ Urban (grey) spaces are “... positioned between the 'whiteness' of legality/approval/safety, and the 'blackness' of eviction/destruction/death. They are neither integrated nor eliminated, forming pseudo-permanent margins of today's urban regions" (Yiftachel, 2009, p. 89). Fractions of such grey space are argued as mini-platforms for powerful change in local neighbourhoods. Contextual issues can be identified at the place-specific neighbourhood to acknowledge that space is particularly transformative at the local area scale, albeit brittle.

Fractional spaces are never quite complete and are involved in the making of micro-parts of the whole, crossing scales, spatial dimensions and their presence amplified over time. They act independently or, if connected, form a mesh of active space reliant on the level of interactions and relationships between the physical and social realms. Details of informal spatial occupation connected to the social production in space are hazy, sometimes silent or persuasively distinct, but are seldom understood as informants for the design of public space. Designing within the public realm requires a new way of questioning the value placed on factional space and how this is translated and represented. Fractional, yet deeply transformative, urban spaces remain largely unrecognised and undocumented from a global south perspective, thereby circumventing inclusion in key municipal spatial frameworks, implementation plans or political decisions, but attract local momentum as places of refuge.

The narrative focuses on a network place-making intervention projects as part of an incremental upgrading programme in Lotus Park informal settlement, located in Gugulethu. The projects are immersed in multidimensional trade-offs and risks. Each fractional space has a unique identity, history and memory, but as a collective they form a safe, integrated precinct.

The practice of co-producing and (re)making urban space in Gugulethu uncovers alternate mechanisms for governance, partnerships and operations. Strategic public investment in Lotus Park as a peripheral site questions place-making practices at multiple scales. If the upgrade of fractional urban space is not connected to city-making, will they remain insignificant and isolated in Gugulethu? This opens

\footnotetext{
3 Fractional urbanism is reviewed by Stillinger's (2015) "energy landscapes, inherent structures and condensed matter phenomena", focusing on the topography of the multidimensional potential energy hypersurface created when a large number of atoms or molecules simultaneously interact with one another. Key aspects that are relevant for this paper are the multidimensional potentials of energy or social activity (people) when they interact in physical public space. Public spaces are seen to have the potential to bind people together in 3-dimenional form, acting as a part or as a network. It is a continuous process.
} 
the debate on how the production of local fractional urban space is anticipated and developed, whilst designed and connected to the city network. The purpose is to expose fractional urban space as continually adapting to the intrusions in the city grid to translate (1) innovative modes of spatial production; (2) dynamic forms of local agency; (3) marginal ways of operating; and (4) interconnected and multi-scalar urban processes. The intention is to inform debate on public space in an African city, offering diverse solutions to stimulate experimental practice and engaged, indirect learning.

\section{Transformative Practice: A Methodology}

Public space has many spatial meanings and social identities in different contexts. Design practice often limits the reflection and exploration of local culture, social influences and micro-economic opportunities in the public realm. Recognising the mechanisms at work in the co-production and (re)making of urban space unpacks a deep description of public space, further exposing thick ways of knowing. There is the need to interpret lessons from process-orientated approaches to find hidden agendas and contradictions in theory and policy. Acknowledging mistakes and their cause are critical to reframing alternative design methodologies.

In conversation with Ayanda Roji ${ }^{4}$ from the Centre on African Public Spaces in 2020, she notes there is a fundamental problem around a lack of understanding and analysis of African public spaces as convivial platforms for collective life. This calls for a more nuanced definition that is context specific and sensitive to alternative forms of space as public. Space that is used for public life is not always considered, authorised, maintained or governed as public space.

Conversations and thoughts on public space have sparked the need to transfer and share stories from transformative practice and engaged learning. The paper offers a form of knowledge exchange, providing a case study on reimagined public space. Perspectives and methods of investigation are based on my empirical spatial role as an architect, urban designer and planner combined with action research and longterm spatial work experience in marginal urban neighbourhoods in Southern Africa.

The first set of reflections on transformative practice are from the Violence Prevention Through Urban Upgrading (VPUU) ${ }^{5}$ programme applied as an area-based approach to Lotus Park informal settlement. Louts Park is considered a VPUU Safe Node Area (SNA) as one of five pilot sites linked to an Informal Settlement Transformation Programme (ISTP) managed by the City of Cape Town (CoCT)

\footnotetext{
${ }^{4}$ Conversation with Ayanda Roji on 17 August 2020 via Zoom in discussion around the Centre on African Public Space with reference to Roji's article https://www.urbanet.info/towards-pan-african-spaces-ofpublic/ accessed on 17 August 2020.

5 Violence Prevention through Urban Upgrading (VPUU) is a comprehensive area-based community development programme that aims towards safe and integrated sustainable communities, citizenship, pride and the improvement of quality of life for residents in low-income neighbourhoods in the Western Cape and beyond. For further reading on the VPUU methodology, refer to Ewing and Krause (2021) (p.344). Joint learning and mainstreaming are developed in alliance with UN Habitat Safe Cities Programme \& Global Network on Safer Cities.
} 
municipality. The paper focuses on VPUU upgrading projects co-produced between 2010 and $2018 .{ }^{6}$ The work during this period was facilitated by a multidisciplinary intermediary, working in integrated teams known as workstreams. ${ }^{7}$ Following a VPUU methodology, ${ }^{8}$ participatory planning methods, including mapping, decisionmaking with stakeholders, co-design workshops and technical meetings, were exercised in a holistic way of thinking about people-centred design.

An active urban design framework, known as a spatial reconfiguration plan (SRP) linked to a community action plan (CAP), assisted the practical problem solving and scenario planning. The layering of the two plans included the prioritisation and location of upgrading projects, responsibilities of different stakeholders, social crime prevention programmes, maintenance and operations, and budgets ${ }^{9}$ over short-, medium- and long-term timeframes. The situational workstream engaged in drawing, photographing, recording and interpreting the changing context. The work recognised different modes of spatial production, self-organisation and social activation of the public realm that questioned the role of place-making and definition of public space both pre-, during and post-implementation. The spatial practitioner acted as many roles: as observer, facilitator, participant, leader and designer to acknowledge new opportunities to emerge through the process. This required careful listening skills, crossing languages and translations of space to recognise new ways of making.

Actors included members from the VPUU Safe Node Area Committee (SNAC), a broader stakeholder group including representatives from youth, women and early childhood development (ECD), ward councillor and municipal sub-council representatives and a range of CoCT departmental staff (integrated as a technical working group), technical experts, an implementing agent Sustainable Urban Neighbourhood (SUN) Development, and VPUU non-profit company and Amandla EduFootball as intermediaries.

In 2010, a participatory process facilitated by SUN was initiated as part of the VPUU Programme. A baseline survey was conducted in 2011 to understand the background and status quo of Lotus Park. Originally, houses were positioned along narrow service lanes with access to electricity, communal water points and shared

\footnotetext{
${ }^{6}$ During this time, the author worked as Workstream Leader: Situational Crime Prevention on the VPUU Programme.

${ }^{7}$ Sustainable Urban Neighbourhood (SUN) Development is an implementing agent for the VPUU Programme Phases 1 to 3. VPUU non-profit company is an intermediary team active in Lotus Park, working with the methodology and strategy of the VPUU Programme. The workstreams included Situational (spatial), Social, Institutional, Project Management, Knowledge Management and Community Participation.

${ }^{8}$ A research-based and participatory methodology is used following a series of logical steps: social compact, planning, implementation, operation and maintenance management and monitoring and evaluation. See Violence Prevention Through Urban Upgrading (VPUU) (2014). Violence Prevention Through Urban Upgrading. A manual for safety as a public good. Retrieved from http://vpuu.org.za/success-story/ vpuu-manual/ (pp. 20-21).

9 Budgets are understood as: micro, under R200,000 (and did not require a tender, limited skilled labour); small, under R2million (for a building under $200 \mathrm{~m}^{2}$, requiring a tender and team of technical experts but focus on skills development and local labour) or medium, under R10million (for a building of $500 \mathrm{~m}^{2}$, lights and sports field, involving a contractor). Detailed prices are not provided in this paper.
} 
toilets. Part of the ground on which families constructed their homes was a previous refuse and landfill site. A mapping exercise, an enumeration process and a spatial survey were initiated in 2012 and continue to be maintained today.

Pressing issues of shelter, sanitation, water, electricity and access to employment overshadowed attention to public space. On average, 10 families shared one toilet and 15 families shared a communal water tap (when they were working) located at specific public locations. Over time, the neighbourhood has grown beyond the original infrastructure and filtered into high-risk areas, further exacerbating access to basic services. Nevertheless, the informal production in space continues to thrive. A UCT student mapping exercise in 2016, 2020 and 2021 revealed a diverse level of micro-economic enterprise across the settlement. Small businesses (spazas, shabeens, salons) were highlighted along key pedestrian movement routes through the area. Informal ECD's were shown dispersed across the neighbourhood, where streets act as outdoor play spaces or micro-public spaces.

The greatest risks in Lotus Park are violence, crime and inequality. In 2016, a VPUU annual household survey highlighted that $45 \%$ of the community perceived crime to be an intolerable regular experience, particularly during the night. Daily risks (robbery, rape and break-ins) were considered more problematic than annual or ad hoc risks (flood, fire, political protests, fear of eviction, etc.). Safety around public space was considered a major challenge.

Practice work is combined with a second set of reflections from engaged learning and teaching in Gugulethu over the past 6 years with the School of Architecture, Planning and Geomatics (APG) at the University of Cape Town (UCT); in 2015 to 2017 with postgraduate architectural students and VPUU ${ }^{10}$; and more recently with urban design and landscape architectural students across Gugulethu. ${ }^{11}$ The lessons are merged with outcomes from a design-build public space project with Cape Peninsula University of Technology (CPUT) undergraduate architectural students in 2016 to $2017 .^{12}$

\section{Space as Public: Theoretical Framing}

Drawing on inspiration from Roy's (2011) position on rethinking subaltern urbanism as an overarching frame contributes to a deeper meaning of the informal production of fractional urban space in an African city. "Subaltern urbanism is (also) a politics of recognition, one that seeks to make visible what McFarlane (2008, p. 341) has called 'urban shadows', "spaces at the edge of urban theory"' (Roy, 2011, p.

\footnotetext{
10 Between 2015 and 2017, VPUU formed a partnership with APG at UCT within the architectural postgraduate programme vertical studio, convened by Francis Carter. The studio allowed students to engage in the reality on the ground in Lotus Park, mapping economic diversity, urban space and understanding the role of the street, interface, threshold and urban form in an informal context.

11 Urban Studio: Gugulethu Hope is a design-research studio course as part of the Master of Urban Design programme within APG at UCT.

12 In 2016 and 2017, VPUU engaged in a partnership with CPUT students through the convener Dr Rudolf Perold around a design-build studio. The partnership resulted in a public space intervention project in Lotus Park. For reference, Perold et al. (2016) (p. 81).
} 
235). Roy seeks to go beyond recognition of the term subaltern, grappling with narratives of subaltern spaces and a disruption of the ontological and topological readings of subalternity through concepts of peripheries (Simone, 2010), urban informality (Roy \& AlSayyad, 2004), zones of exception (Ong, 2006) and grey spaces (Yiftachel, 2009). I argue most of these theoretical categories intersect in fractional space.

The first frame focuses on the evolution of peripheral urban space in the Lotus Park precinct through Caldeira's (2017) theory on peripheral urbanisation and the modes of the production of (informal) space. To compliment Roy's discussion, Caldeira (2017) reasons, "What makes the process peripheral is not the physical location but rather the role of residents in the production of space and how as a mode of urbanisation it unfolds slowly, transversally in relation to official logics, and amidst political contestation" (p. 4). However, it cannot be avoided that, "Peripheries are, undoubtedly, about inequality" (Caldeira, 2017, p. 9).

A second frame is expressed through Berney's (2011) exploration into citizen spaces as pedagogical urbanism involving a "mode of urban development focused on citizen education and reform that produces figurative and material space in the city for educational encounters" (p. 17). Berney (2011) addresses the definition and role of public space as a point of encounter of the 'other' and a "comprehensive fix". Spaces of reform fall on a range between "free and disciplined space, based on the scale, design, programming, degree of private investment, the presence or absence of citizen groups and city employees in the space; thus each space will shape and be shaped by citizens in unique ways" (p. 30). The key to her argument are crosscutting scales related to urban processes.

It is the multi-scalar affiliation of cities, space and society that is dynamic and difficult to predict, decode and understand. Berney (2017) explores the intertwining of new public space intervention projects connected to city-scale public transport implementation. ${ }^{13}$ She argues that an urban vision enables the reclamation of (privatised) public space and the refurbishment of neglected open space across the city. Such spaces need to be designed within an accessibility network and supported through relevant governance. Berney $(2010,2017)$ illustrates the connection between strategic city-led projects at multiple scales, formal politics and smart urban planning linked directly to social strategies on the ground.

The third frame expands to include Bayat's (1997) theory of quiet encroachment as an everyday informal practice, "a silent, patient, protracted and pervasive advancement of ordinary people on the propertied and powerful" (p. 57). Bayat (1997) recognises that urban appropriation of space is tentative, incremental and motivated by everyday politics and needs, particularly in a context where the state functions on a partial level or in defiance of plans (Lawhon et al., 2018). Potentially what is missing is the application of political agency

\footnotetext{
13 Caldeira (2017) juxtaposes dissimilar cases from cities of the Global South, particularly São Paulo. Berney's $(2011,2017)$ work is the city of Bogotá. Bayat's (1997) work references experiences from cities in the Middle East. These theories have been intentionally reviewed for their studies in the Global South urban context.
} 
to context (Gillespie, 2017). However, he provides a thoughtful debate on the struggle over urban space through a "dialect of individual and collective action" (Bayat, 1997, p. 66). Bayat's theory is complimented by McFarlane's (2008) understanding of infrastructure development that offers a framework to study the urban fabric, where the case study presents "the contestation of the distribution and redevelopment of infrastructure" (p. 352).

\section{Learning from Lotus Park: Tracing Urban Intervention Projects as Fractional Spaces}

An important lesson from practice, research and teaching is to understand the intersectional socio-spatial nature of fractional urban spaces. It is positioned within the frame of informality and peripheral urbanisation, having the ability to "transcend territorial location" (Roy, 2011, p. 232). Dovey (2019) highlights, "The challenge of engagement with urban informality requires fundamentally different modes of thought and practice," where, "Urban informality is a mode of production of public space, and therefore a form of urban design." (p.139).

Roy (2011), Roy and AlSayyad (2004) asserts informality is "a logic through which differential spatial value is produced and managed", where, "Urban informality then is not restricted to the bounded space... it is a mode of the production of space that connects the seemingly separated geographies of slum and suburb" (p. 233). Roy (2011) further continues where, "The splintering of urbanism does not take place at the fissure between formality and informality but rather in fractal fashion, within the informalised production of space." (p. 233).

A set of tracings, integrated with theoretical frames, reveal the impact of informal upgraded urban space in Lotus Park through firstly, emerging centres and the (re)making of place on the periphery; secondly, disrupting edges and the coproduction process involved in the negotiation of space; and lastly, crafting shadows and interpreting traces of micro interventions. The intention here is not to revise or debate theoretical concepts in depth but to explore what lies hidden in the complexity of fractional urban space through direct experience from practice in a southern context.

\section{Emerging Centres}

Lotus Park has for a long time been considered a peripheral, informal and precarious neighbourhood, regardless of the relatively central location of Gugulethu in Cape Town. The informal settlement was established on a fragmented island of land, sandwiched between a railway line and a canalised (open) river. Land is documented as undetermined, being considered unrecognised by planning legislation. Formal ownership of the land is complex and held within two different spheres of institutional governance (a parastatal and local government) but occupied by over 5000 residents. 
The area is, however, adjacent to the Nyanga Junction railway station and economic hub, potentially connecting the neighbourhood to the larger city network and providing local possibilities for a well-located, mixed-use integrated development in the future with the capacity to redirect public and social investment. Nevertheless, with the south-east metro train line no longer functioning and unreliable taxis and buses, the lack of connectivity to the broader Cape Town increases the vulnerability of the residents, highlighting not only the levels of inequality in the city, but showing the uncanny resilience and determination of the neighbourhood.

At a precinct scale, over the past 10 years, a neglected space has been incrementally upgraded changing the dynamic and perception of public space within the community. The Lotus Park precinct has become a concentration of safety, acting as a magnet for the youth and a meeting place for all. Periphery in the Lotus Park context is further viewed following Simone (2010) as a "potentially generative space - a source of innovation and adaptation... potentially destabilising the centre" (p. 40) (as quoted in Roy, 2011, p. 232). Supported by Holston and Caldeira (2008) thoughts as, "Sites of metropolitan innovation", that "often emerge at the very sites of metropolitan degradation" (p. 18). Yiftachel (2009) argues grey spaces occur at the periphery by necessity, often associated with danger, as a "potential zone of societal transformation" (p. 92). Complimented by Berney's (2011) argument that public space is conceived as "the key sites for the reproduction of citizens and a catalytic site for the reproduction of the city" (p. 21). It is the smaller, fractional spaces or sites of innovation where the intervention of urban projects appears to have elasticity and the momentum for change.

The narrative moves to a project known as the Lotus Park neighbourhood centre (as in a building), as seen in Fig. 1. The proposal for the community facility was considered a medium-term, high-priority project by the stakeholders in the community action plan. A portion of unclaimed, informal and neglected municipal land was identified by stakeholders, the intermediary and the local municipality to the north of Lotus Park as a site for the neighbourhood centre to be constructed. Originally, the building was seen to have the potential to act not only as a place to cater for the needs of the community, but also as an emerging centre and catalyst towards a safe and integrated precinct.

In 2011, the area consisted of a smouldering rubbish dump with goats as frequent visitors to the space. An existing patch of grass where young children kicked a ball was highlighted as a public space. A busy scrapyard occupied a portion of land to the west. Barber shops, spazas and braai stands edged the surrounds in an orderly, yet transitory fashion. A derelict creche stood to the north. After a lengthy engagement with the municipality on the status of the site and future use as a public building, a set of building plans listed for temporary occupation was approved. Between 2012 and 2014, the stakeholders co-produced a local neighbourhood centre made from eco-beams, sandbags and shipping containers around a series of flexible, open and covered spaces. The building was seen to act as a beam of light and act as a "safe active box" (Ewing \& Krause, 2021). Today, the neighbourhood centre is a spatial gateway to the settlement, whilst also providing a stable home for the community leadership, local 


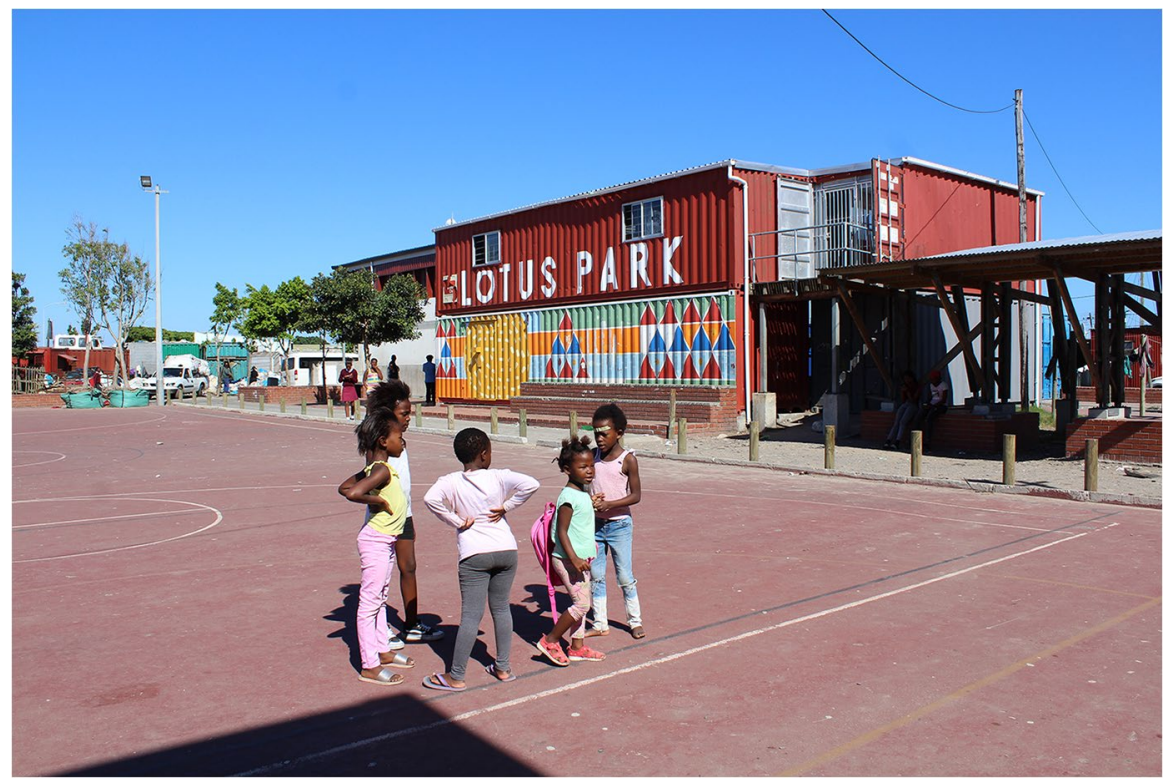

Fig. 1 March 2019, Co-production and the making of a new centre on the periphery, Lotus Park neighbourhood centre

organisations, small businesses, youth and sports groups, a toy library and VPUU non-profit company offices.

After deliberation with numerous stakeholders, in 2015 an open portion of land (the former grassy patch) was upgraded adjacent to the neighbourhood centre as an open hard-court with lights. The hard-court is referred to as "emthonjeni", ${ }^{14}$ a term defined as a as a multifunctional place that can evolve (or disappear) over intervals (Ewing \& Krause, 2021, p. 347). The proposal put forward by the community was for a single-use soccer field. The design trade-off was to allow for various activities to take place to be more inclusive of different members of the community by painting lines for not only soccer, but also netball and basketball. Today, the hard-court hosts young children singing and playing games in the morning, to a range of ages practising different sporting disciplines in the afternoon. On Saturday morning, the space converts to a keep-fit stage and by the afternoon it hosts a soccer game. On Sunday, the public space provides a venue for the church as an outdoor place of celebration. The site is used for formal girls' league netball games throughout the week

\footnotetext{
14 The description of "emthonjeni" is provided in Ewing and Krause (2021), "The isiXhosa word emthonjeni refers to "being at the fountain"- a place by the water... The upgrade of small scale emthonjeni is a practical solution to improve safety as they create safe places for children to play and for the provision of selected managed utilities and services. These spaces are focused internally to the neighbourhood cluster and encourage social cohesion. They are located along pedestrian desire routes and are the breathing space along pathways which connect neighbourhoods. Clustering around small open spaces helps to provide space for economic opportunities and assist in providing safe public spaces close to home" (pp. 347-348).
} 
as the lights provide extended playtime, thereby connecting the settlement to the city as a new centre and a place on the map.

The Oliver Kahn Gugulethu-Manenberg Safe Hub@ and astro turf sports field and lights were constructed between 2014 and 2017 on a portion of secondary school land that was formally surveyed and zoned adjacent to Lotus Park. The sports field, hosting four 5-a-side fields, and Safe Hub building are managed and maintained by an intermediary, Amandla Edufootball. On Friday evenings, the precinct, from the (informal) neighbourhood centre to the (formal) safe hub, is activated by sports programmes and supported by small-scale informal businesses. People gather to watch the events and access free Wi-Fi at the youth café.

A VPUU annual household survey in 2016 reflected that $94 \%$ of the residents interviewed were aware of the neighbourhood centre, safety hub and sports fields. This was further acknowledged by community members on a site walk-about in 2020 where the neighbourhood centre was identified as a new landmark in Gugulethu a place to access information. The physical and social connection between the two community buildings, hard court and the sports field creates a safe and accessible precinct planned within an active spatial reconfiguration framework.

\section{Disrupting Edges}

Disrupting edges give reference to the intersectional relationships of people and space. Contestation and friction over public space often led to more dynamic solutions. Carmona (2010) reasons, "urban public space shapes and is shaped by society - its power relationships, priorities and its fears" (p. 158). Critical to the argument is Caldeira's (2017) angle that peripheral urbanisation consists of "a set of interrelated processes that entangle citizens and states in the production of cities of great heterogeneity and dynamism" (p. 15). Friedmann (2007) argues that the strength of a region is its people and their ways of life, where "engaging local citizens in a common effort by giving them a stake in the future of their city" (p. 997), encouraging trust and transparency in development. Participatory planning and co-design or coproduction is not a new concept (Watson, 2014), yet the way in which we engage in multi-sided conversations and negotiating space presents a new dialogue that has changed substantially over the past 10 years, particularly within municipality.

As part of the incremental design process, an early childhood development (ECD) centre, as seen in Fig. 2, was constructed in the Lotus Park precinct. The small, permanent, brick building took 4 years of intense collaboration aligned to the CAP and SRP. The building formed an important permanent edge and defined interface to the hardcourt. A new community garden created a buffer to the railway line and changed the sense of boundary into a new form of porous threshold. The ECD centre also connected the neighbourhood centre activities of the toy library into a shared, childfriendly, safe space allowing for encounter and learning.

There were multiple stakeholders involved in the process, including a community-based ECD organisation, the CoCT (local) and Western Cape Government (provincial) as key partners. Today, the centre functions under a Montessori curriculum 


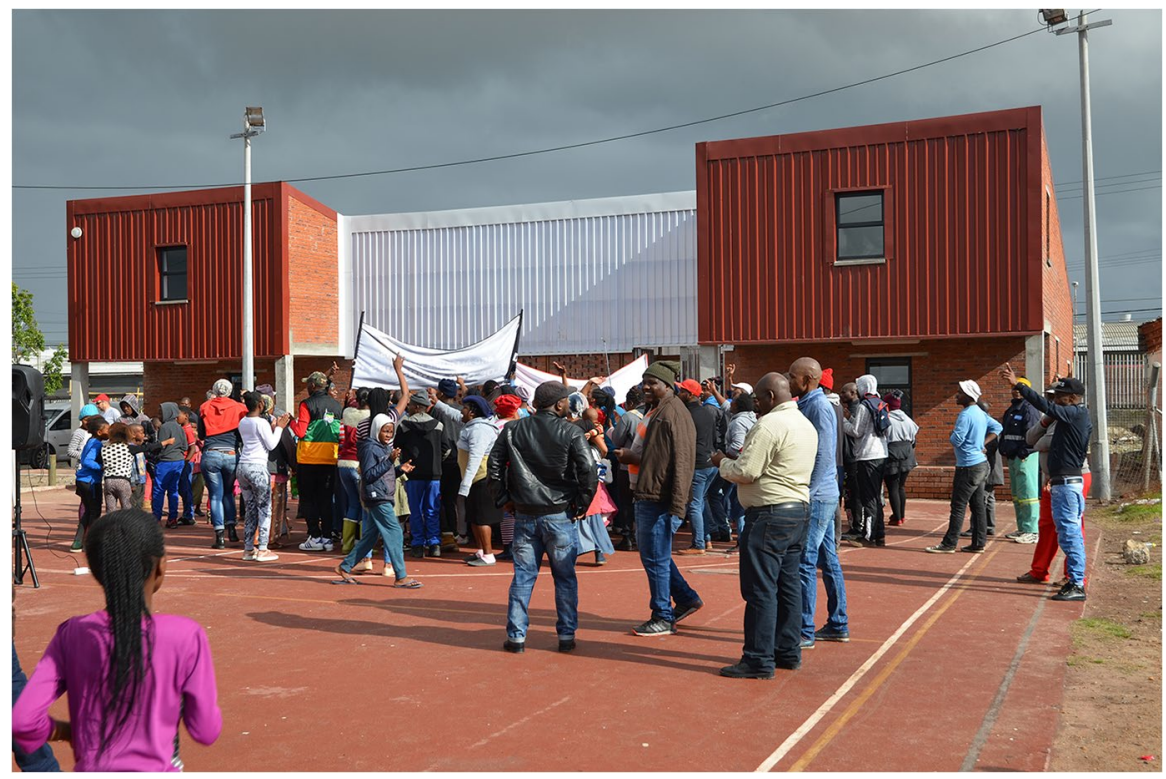

Fig. 2 July 2018, Negotiations and trade-offs on the edge with the Lotus Park early childhood development centre

with a wider role as an ECD hub for teaching support and leadership development beyond Lotus Park.

On the opening day, the celebration started with a political protest on the hardcourt, outside the doors to the ECD centre. The event and space created a platform for a rich dialogue around service delivery and the implementation of projects. Protesters demanded questions around the lack of service delivery in Gugulethu. Is the delivery of teaching and learning in a positive environment for young children not a form of social infrastructure so desperately needed in an informal context? McFarlane (2008) reasons, "The expansive conception of the relation between infrastructure and social change sketched (here) engages with the actions of a wide variety of actors and multiplies the potential sites of intervention, from water pipes, drains and power stations to laws, policies and officials" (p. 355). The moment of disruption in Lotus Park encouraged discussions with both provincial and municipal governments on the relaxation of standards around the upgrade of ECD facilities in informal settlements and the ability for ECD's to receive buildings plans approval, thereby facilitating access to government subsidies. The sense of social infrastructure creep as the precinct encroached into new territory, albeit continually under duress, opened a new avenue for transformative practice.

The second project relates to both the designer and community having agency. Students from Cape Peninsula University of Technology (CPUT) approached VPUU to design and build a public space project in Lotus Park. At the start, both students and community members felt intimidated to engage. Students placed crisp designs on clean sheets of paper, pinned to the wall, awaiting review and input. However, 
community members were uncertain about the consequence of making decisions based on technical drawings. After a review by the staff and intermediary, the students came back 2 weeks later with rough models that were discussed in groups around a table involving collective decision-making. The small gesture of inclusion from both sides changed the nature of the design process. The outcome was a merged design that filtered in many of the community concerns and student ideas.

The project became known as the "bus stop" shelter. The chosen location was at a key point, edging the urban space. The combinations of students learning through practice, community members understanding construction implications and local labour working with materials like steel were complex ingredients for a small-scale, micro-budget intervention. The project stood tentatively hanging onto the neighbourhood centre until the ECD centre was built. The shelter now gently connects the two buildings. It acts as a jungle gym for the children, a shelter for the netball players and youth to hang out. Over time, incremental landscaping has merged the urban upgrading projects into a more defined, yet permeable boundary, symbolising the occupation of fractional urban space.

\section{Crafting Shadows}

Friedmann (2007) argues that, "Most of us live our lives quite locally, not universally, and we treasure the small spaces of the city..." (p. 992). What is imperative is not to over-design informal public space, but to leave room for democratic negotiation and ingenuity - Sennett's (2007) notion of "incomplete space". The viewpoint leans towards Storey's (2014) creative or invented spaces rather than creating invited places for others, revealing the need for positive traces of co-produced micro-interventions. Caldeira (2017) expresses "spaces that never quite done, always being altered, expanding and elaborated on" (p. 5), where they operate with a "specific form of agency and of temporality" (p. 4). "Their spaces are always in the making... neighbourhoods and homes grow little by little, in long-term processes of incompletion and continuous improvement led by their own residents" (Caldeira, 2017, p. 5).

Bayat (1997) alludes to an "active use of urban space" (p. 54) in the "streets" (with reference to alleyways, pavements, public parks and sports areas) as an "arena of politics" (p. 63), part of everyday practice that are not tolerated by authorities. However, in Lotus Park, the projects were developed and activated with the authorities input and/or knowledge. What is critical to understand are the micro-interventions acting as a network. Bayat (1997) gives reference to the "passive network" (p. 64), requiring a degree of organisation, communication and networking amongst actors. "The street as a public place possesses this intrinsic feature making it possible for people to mobilise without having an active network" (Bayat, 1997, p. 64). However, the argument in Lotus Park reinforces the idea of active frameworks that connect the smaller less significant and individual spaces.

The first project focuses on the Lotus Park scrapyard. It is operated by an outsider from the community which has always been a concern for the residents in Lotus Park. Sitting side-by-side, the neighbourhood centre and scrapyard have managed a relationship of embattled coexistence over the past number of years. There was, 


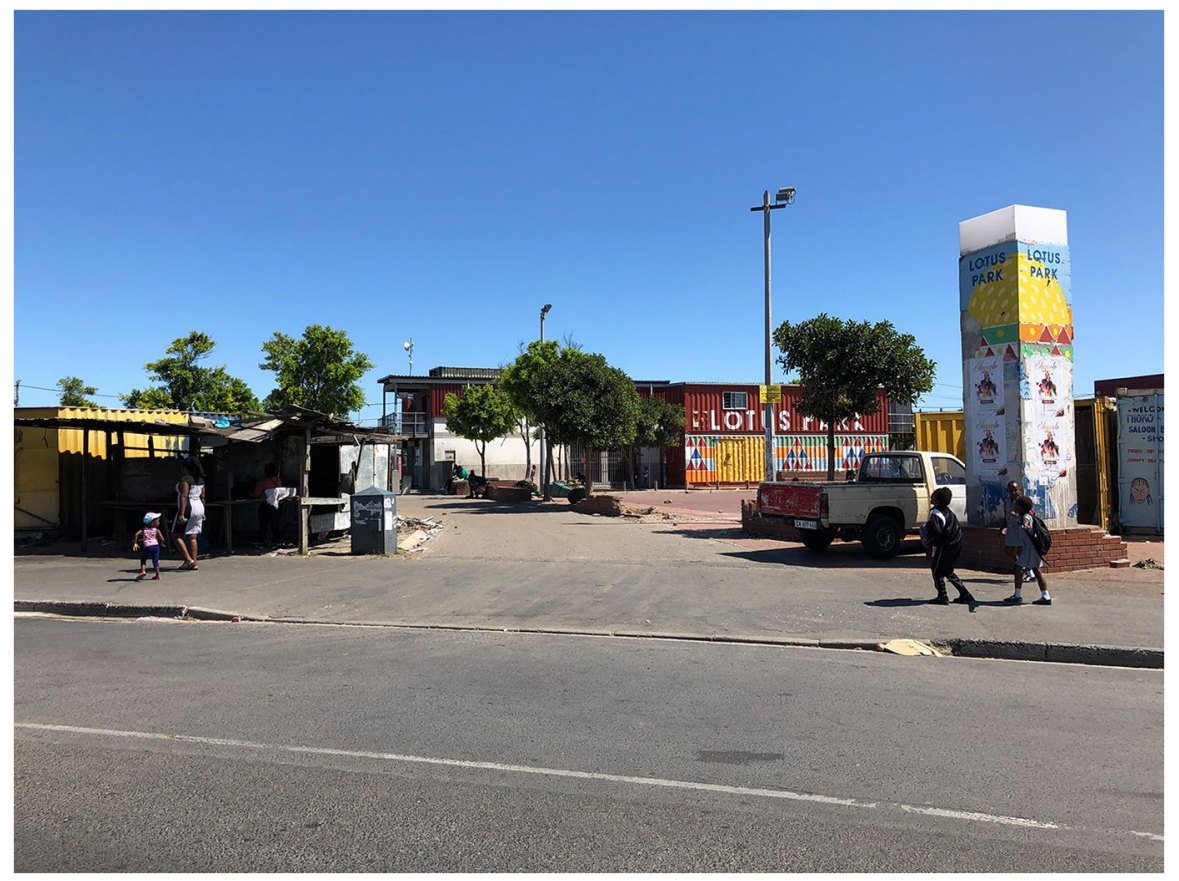

Fig. 3 March 2020, Changing shadows and defining space and identity through the Lotus Park signpost

and continues to be, a constant pulling and pushing over this fraction of $400 \mathrm{~m}^{2}$. Legal ownership remains with the local municipality. On the one hand, the centre provides a safe active box for the community. On the other, the scrapyard provides a minimal livelihood to the community, entrenched in the economic underworld of buying and selling illegal scrap metal and recycled plastic. Both fractional spaces were considered transitory, constantly expanding, or contracting, driven largely by local temporal agency and everyday community need, combined with a commitment to a broader sense of transformation.

In 2016, twelve trees were donated by the CoCT towards the upgrade of urban space around the neighbourhood centre. Many intense and heated negotiations took place with the actors involved from the community, local leadership, scrapyard operator and intermediary. Over the years, a few trees were planted, nestled within and around the operations of the scrapyard and the new ECD. The planting of the trees signified the long-term green infrastructure growth and public investment. The trees, however, also signified a subtle take-over or a quiet encroachment of the scrapyard. In 2020, a waste recycling centre was established adjacent to the new ECD, further casting a new dynamic and reoccupation of space.

The second project relates to a distinctive way of community place-making. In 2015, the community and VPUU designed a signpost, as seen in Fig. 3, at the entrance to Lotus Park along the NY3 street, giving direction from the train station. The area was becoming a popular destination to residents outside the area since the installation of lights allowed for weekly nighttime sports events. With a 


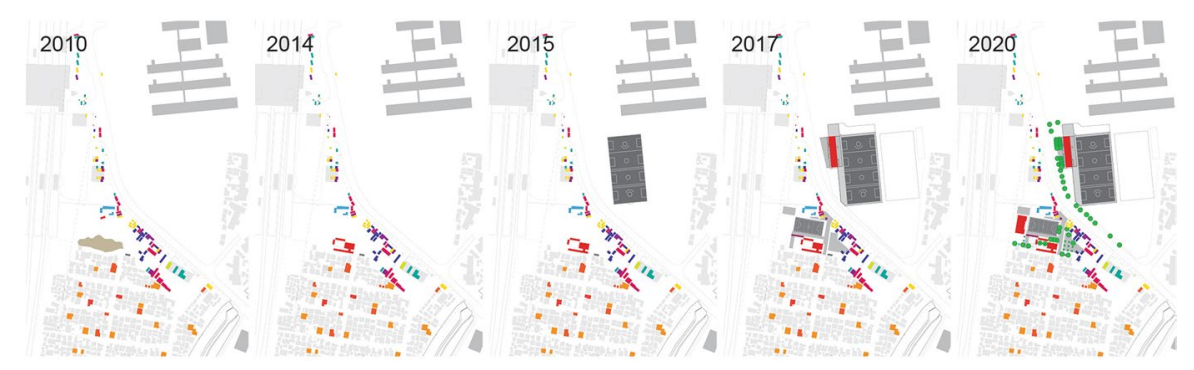

Fig. 4 Incremental and strategic place-making in the Lotus Park Precinct over 10 years of upgrading

micro-budget and limited resources, a brick signpost with a light inside was constructed by the VPUU local labour team. Cape Town-based arts collective See-SawDo and community members painted the signpost and marked "Lotus Park" to the side of the neighbourhood centre, instantly giving an address to an informal context. The post and Lotus Park sign are still visible today, although in need of a repaint. The small, insignificant project had a big impact on the (re)making and claiming of fractional urban space.

The last shadow is an idea or project in-the-making, known as the Gugulethu Wall of Hope. The urban project is a youth-focused, public space proposal based in Gugulethu but stretching the impact beyond Gugulethu. It was initiated in 2020 through a series of participatory workshops within a design-research studio exploring public space in Gugulethu as part of the UCT Master of Urban Design (MUD) Programme. The intention is to implement the Wall of Hope as a design-build student-community project in the future, potentially mobile, temporary and tactile, but located within an active public space framework for Gugulethu.

\section{Translating Fractional Urban Space in Lotus Park: Takeaways}

The re-making of urban space in Lotus Park shows the synthesis and production of anticipated design in context that identifies transformation at the core. Fresh attitudes to design approaches along with governance (ownership and planning), partnerships (co-design and activation) and operations (implementation and maintenance) are required to reframe the meaning and value of public space. Learning from Lotus Park offers a practical translation of fractional urban space resulting in the following four take-aways.

1. Innovative modes of spatial co-production - designing implementation projects for social intervention

Urban design is framed as a strategic, situated, incremental and negotiated place-making process, giving reference to design as active (on-going) to guide practical spatial strategies and intervention projects, as seen in Fig. 4. Planning for informal settlement upgrading programmes, where implementation, activation, 
operations and maintenance are linked to a holistic people-centred and area-based approach, requires spatial reconfiguration frameworks to guide development.

The SRP aligned to the CAP in Lotus Park allowed the actors to anticipate potential solutions, whilst designing for varying constraints and challenges at a local scale. The co-produced urban projects with transparent budgets and timeframes for construction helped shape a more aware citizenry and politicians alike in Gugulethu. Individually, the projects supported critical decision-making processes that tested urban design practice at a collective level (including policy, costs, delivery, monitoring and evaluation and impact). A key land-use component was to implement projects on publicly owned land, even if not zoned or considered (in)formal, indirectly situating the responsibility into the realm of municipality, but providing a sense of ownership to the community. Public investment (even if funded via partnerships, NGOs, etc.) in fractional urban space is crucial in areas that have minimal access to valuable outdoor space and resources to implement projects in the public realm.

2. New forms of local agency - designing space to expand and contract with multiple stakeholder engagement

Transformative practice demands a committed and intentional multidisciplinary approach guided by diverse inputs, needs and stakeholders. The roles and responsibilities of local actors and strategic partners involved in the urban upgrading process in Lotus Park were acknowledged as having complex co-dependencies with differing synergies and interconnections that were sometimes disguised or altered over time. Joint decision-making and co-production are never easy but are necessary for collaborative outcomes and broader advocacy beyond the precinct. Not all stakeholders had equal powers, responsibilities and actions during the place-making process, linking to Caldeira's (2017) notion of transversal logics where "citizens and governments interact in complex ways" (p. 7). Although the active community leadership of Lotus Park was key to the co-production of space, the local municipality played an oversight role in the urban upgrading programme (albeit sometimes unsuitable, technical and legislated). The intermediary role was key to enable effective and productive partnerships between all actors and funders where there was accountability through responsible co-production at all stages of the process. Unexpected collaborations surprisingly enhanced the diversity of intervention projects in multiple ways.

3. Marginal ways of operating - designing for unexpected and unplanned microinterventions and activities

The vision of fractional urban space considers the idea of a "quick-quick-slow" approach, like a dance. Quick-spend, micro-budget projects, with rapid implementation that have visible outcomes, guide gradual, permanent, lasting change. All choreographed through a lively process or reference to active frameworks. Unexpected uses in the smallest of spaces and various forms of activation after implementation contribute to the versatility of social life. The vision is to plan creatively and act in parallel to create a stage for social infrastructure to flourish. Incremental place-making is not a linear step by step method but one of backward and forward, from discussions and actions at the visioning stage to the designing and implementation stages. Projects need to be carefully anticipated, planned and 
developed, requiring financial commitment from stakeholders and partners at the outset.

4. Interconnected and multi-scalar urban processes - designing for capacity building and social networks

In many instances, public space is only arranged at a very local scale, thereby having little effect outside of the neighbourhood boundaries. Projects may be perceived as one-offs where knowledge remains local and unrecorded. However, there is an on-going changing level of involvement and interest from the public beyond Lotus Park in improving the informal settlement. Social and learning programmes (netball league, ECD resource hub, smart networks, academic interest and student involvement and learning) have stretched beyond Gugulethu. Local leadership groups from Khayelitsha, Paarl and Villiersdorp (outside of Cape Town) visit Lotus Park as part of learning exchange workshops - swopping stories and lessons, deliberating mistakes, planning events and understanding costs for maintaining and operating fractional urban space. Local municipal and provincial officials also visit the site to understand the how-to aspects of informal settlement upgrading and area-based management. A major downfall in the Lotus Park case study is the eroding spatial link to the city-scale network, rendering the transformation projects as isolated.

\section{Remarking: In Conclusion}

Radical change in urban space is persistent where the urban fabric is understood as an evolving system. Hereby, rendering the future of fractional urban space as ambitious, energetic and, most likely, contested. Fractional spaces create adaptable sites for numerous political questioning, social conflict and productive economies. Reimaging neglected urban space releases the possibility for connection and social cohesion, allowing fractional space to prosper through the smallest of (design) interventions. Co-producing design projects allow for the testing of scenario-orientated typologies (centres, edges, shadows) as fractional urban space, framing the public realm (or precinct) as transformative and represented.

Careful place-making of relatively small-scale intervention projects disturbs the perception of public space at multiple levels. Marking solids and voids for (re)occupation and crafting porous interfaces to open and closed individual spaces provide the threshold to hold fractional spaces as a connected public mesh or collective safe and active space. Each fraction, linked to a flexible spatial programme, allows for everyday encounters to take place as an integral part of self-empowerment and social networking. It is also in these physical spaces that we can more positively memorialise and integrate the past through social dialogue, debates and celebrations. Recognition of fractional urban spaces as key social infrastructure for learning, practice and exchange marks a real possibility for long-term permanent action, consolidation and intensification, creating a new sense of belonging and identity. 
Acknowledgements This paper has been in-the-making over many years, intertwined with life, practice and teaching. With thanks to community members in Gugulethu, SUN Development, City of Cape Town, UCT, CPUT, Amandla EduFootball and multiple other partners that I have engaged over the past 10 years. Special acknowledgement is given to Violence Prevention through Urban Upgrading (VPUU) nonprofit company (NPC) for their inspiration, innovation and commitment to on-going social change and transformative practice. It is noted that the author is a non-executive Director of VPUU NPC. Thank you to local leaders, in particular Xolile Ndzoyi for the on-going dedication to co-creating safe space and local knowledge exchange. There are too many participants, colleagues, fieldworkers, friends, lecturers and students to name on an individual basis, but my thanks go out to you all.

Funding The author received no direct financial support for the authorship and/or publication of the article. However, reference is given to the University of Cape Town Engaged Scholarship Programme 2019, where the author attended a series of workshops which ignited the interest to write the narrative of engaged spatial practice. A further Socially Responsive Course Development Grant based on engaged learning awarded to the author in 2019 to 2020, combined with a UCT Teaching and Learning Grant and support from UCT APG facilitated on-going research and teaching in Gugulethu in 2021.

\section{Declarations}

Conflict of Interest The author declares no competing interests.

Ethics Current research and teaching related to the Wall of Hope and Urban Studio: Gugulethu Hope received ethics approval by the University of Cape Town in 2020 and 2021.

\section{References}

Bayat, A. (1997). Un-civil society: The politics of the "informal people." Third World Quarterly, 18(1), 53-72. https://doi.org/10.1080/01436599715055

Berney, R. (2010). Learning from Bogotá: How municipal experts transformed public space. Journal of Urban Design, 15(4), 539-558. https://doi.org/10.1080/13574809.2010.502344

Berney, R. (2011). Pedagogical urbanism: Creating citizen space in Bogotá Colombia. Planning Theory, $10(1), 16-34$

Berney, R. (2017). Learning from Bogotá: Pedagogical urbanism and the reshaping of public space (1st ed.). University of Texas Press.

Caldeira, T. P. (2017). Peripheral urbanization: Autoconstruction, transversal logics, and politics in cities of the global south. Environment and Planning d: Society and Space, 35(1), 3-20. https://doi.org/10. $1177 / 0263775816658479$

Carmona, M. (2010). Contemporary public space, Part Two: Classification. Journal of Urban Design, 15(2), 157-173. https://doi.org/10.1080/13574801003638111

Dovey, K. (2019). emopenInformal settlement as a mode of productionemclose (1st ed.). Routledge.

Ewing, K., \& Krause, M. (2021). Emthonjeni - Public space as smart learning networks: A case study of the violence prevention through urban upgrading methodology in Cape Town. In A. Aurigi \& N. Odendaal (Eds.), Shaping smart for better cities (pp. 339-356). Academic Press.

Friedmann, J. (2007). The wealth of cities: Towards an assets-based development of newly urbanizing regions. United Nations Human Settlements Programme.

Gillespie, T. (2017). From quiet to bold encroachment: Contesting dispossession in Accra's informal sector. Urban Geography, 38(7), 974-992.

Holston, J., \& Caldeira, T. (2008). Urban peripheries and the invention of citizenship. Harvard Design Magazine, 28, 18-23.

Lawhon, M., Pierce, J., \& Makina, A. (2018). Provincializing urban appropriation: Agonistic transgression as a mode of actually existing appropriation in South African cities. Singapore Journal of Tropical Geography, 39(1), 117-131.

Mabin, A., Butcher, S., \& Bloch, R. (2013). Peripheries, suburbanisms and change in sub-Saharan African cities. Social Dynamics, 39(2), 167-190. https://doi.org/10.1080/02533952.2013.796124 
McFarlane, C. (2008). Urban shadows: Materiality, the 'Southern City' and urban theory. Geography Compass, 2(2), 340-358. https://doi.org/10.1111/j.1749-8198.2007.00073.x

Ong, A. (2006). Neoliberalism as exception : Mutations in citizenship and sovereignty. Duke University Press.

Perold, R., Donaldson, R., \& Devisch, O. (2016). Grounded architectural practice: Exploring spatial capacity building in informal settlement upgrading. South African Geographers, 78

Roy, A. (2011). Slumdog cities: Rethinking subaltern urbanism. International Journal of Urban and Regional Research, 35(2), 223-238. https://doi.org/10.1111/j.1468-2427.2011.01051.x

Roy, A., \& AlSayyad, N. (2004). Urban informality: Transnational perspectives from the Middle East, Latin America, and South Asia. Lexington Books.

Sennett, R. (2007). The open city. In R. Burdett \& D. Sudjic (Eds.), The endless city: The Urban Age project by the London School of Economics and Deutsche Bank's Alfred Herrhausen Society (pp. 290-297). Phaidon.

Simone, A. M. (2010). City life from Jakarta to Dakar: Movements at the crossroads. Routledge.

Stillinger, F. H. (2015). Energy landscapes, inherent structures, and condensed-matter phenomena. Princeton University Press. https://doi.org/10.1515/9781400873975

Storey, A. (2014). Making experience legible: Spaces of participation and the construction of knowledge in Khayelitsha. Politikon, 41(3), 403-420. https://doi.org/10.1080/02589346.2014.975935

Venter, Z. S., Shackleton, C. M., Van Staden, F., Selomane, O., \& Masterson, V. A. (2020). Green apartheid: Urban green infrastructure remains unequally distributed across income and race geographies in South Africa. Landscape and Urban Planning, 203, 103889. https://doi.org/10.1016/j.landu rbplan.2020.103889

Watson, V. (2014). Co-production and collaboration in planning - The difference. Planning Theory \& Practice, 15(1), 62-76. https://doi.org/10.1080/14649357.2013.866266

Yiftachel, O. (2009). Theoretical notes on 'gray cities': The coming of urban apartheid? Planning Theory, 8(1), 88-100. https://doi.org/10.1177/1473095208099300

Publisher's Note Springer Nature remains neutral with regard to jurisdictional claims in published maps and institutional affiliations.

\section{Authors and Affiliations}

\section{Kathryn Ewing ${ }^{1}$}

Kathryn Ewing

kathryn.ewing@uct.ac.za

1 Department of Architecture, Planning and Geomatics - Urban Design, University of Cape Town, Cape Town, South Africa 